\title{
Earning like a Prof: Academic rank wage premia in Ústí nad Labem, Czechia
}

\author{
Daniel Štastný ${ }^{1}-$ Julius Janáček $^{2 \otimes}$ \\ ${ }^{1}$ University of New York in Prague, Praha, Czechia \\ ${ }^{2}$ Faculty of Social and Economic Studies, J. E. Purkyně University, Ústí nad Labem, Czechia \\ 凶uliusjanacek@post.cz
}

\begin{abstract}
The article attempts to estimate the size of the wage premia fetched by ranked academics on the academic market in Ústí nad Labem, Czechia. We employed a large (anonymized) data set of contracts and wages of employees of a medium-sized regional public university in Ústí nad Labem. We used OLS regression in various specifications to determine the wage premia of all educational levels (mainly full professors over associate professors/docents and associate professors/docents over assistant professors/PhDs) while controlling for many attributes (of employees or contracts) possibly affecting wage levels. The local context regarding the topic of this article is discussed as well. The results generally confirm the intuition and show a clear pattern of increasing wages with levels and ranks. Focusing predominantly on the academic ranks, the monthly premium of associate professors (docents) over PhDs seems to be somewhere between 5 and 6 thousand CZK (185 and 220 EUR), and the premium of full professors over associate professors to an average of around 4 thousand CZK (150 EUR). The latter premium, however, exhibits systematic variation across different schools within the university: in some it is insignificant (around 0), while in others it is rather large and averages around 8 thousand CZK (300 EUR).
\end{abstract}

\section{Highlights for public administration, management and planning:}

- The monthly premiums of academic ranks are studied on the example of the regional University of Jan Evangelista Purkyně in Ústí nad Labem (Ústecký region).

- The monthly premium of associate professors (docents) over PhDs is between 5 and 6 thousand CZK, while the premium of full professors over associate professors averages around 4 thousand CZK.

- The premium of full professors over associate professors is lower than the premium of associate professors over PhDs and exhibits greater variation among different schools within the university.

\section{Introduction}

While the link between wages and productivity is common knowledge in economics, the notoriously challenging part of that equation is the quantification of productivity. Short of situations with perfectly measurable productivity, it is approximated by other proxies, most notably seniority or organization hierarchy rank. Wages then tend to reflect that discontinuity and exhibit premia associated with various positions and ranks.

On the academic market in particular, academic ranks reflect past achievements in research

\section{Keywords}

Academia, Wage premium Accreditation Ranks

\section{Received:}

02 August 2021

Received in revised form: 10 November 2021

Accepted:

29 November 2021 and pedagogy of faculty, and assuming they are indicative of faculty's current performance as well, ranks are rewarded with a premium. Although the motivation to reach a higher rank is strong across different regions of Czechia, it can be expected that the wage premia will differ across different regions. In this sense our article is a case study focusing on regional particularities.

In this paper, we exploit wage and employment data of one regional, middle-sized university in Czechia to cast some light at the university faculty wage premia across different Czech academic titles/ranks, namely the PhDs, the docents and the professors (which is roughly the equivalent to the assistant, 
associate and full professors). Specifically, our research objective is to measure the size of the nominal wage premium of:

- Docents (associate professors) over PhDs, and

- Professors over docents.

The motivation for these premia in particular is the fact that academic ranks have long been considered a major factor in granting accreditations to Czech higher education institutions (HEIs) by the Czech government authorities, which adds extra value universities derive from ranked faculty that goes beyond faculty's performance in research and teaching per se. This analysis gives some empirical content to all of these intuitive notions that higher academic ranks associate with higher wage and enables us to quantify the value that the academic labor market tends to put on individual ranks.

The school studied in this article is the University of Jan Evangelista Purkyně in Ústí nad Labem. It is the only university in the region. Founded in 1991, it is a rather young institution in comparison with many other Czech universities. Being situated in the central city of the Northwest region, the founding of the university reflected the region's need for people with higher education. Currently, there are more than 12000 students in 8 schools belonging to the university. The wages in the university are naturally related to wages in the region, whose average level is known to be below the country's average. The question is of course whether one can assume the wage level to have any systematic impact on relative wages, i.e. the wage premia that are the focus of this article. In the context of the whole country the university we are investigating suffers from peripherality and low attractivity of the region. It is possible that this aspect must be countered by adjusting the wage premia of higher academic ranks. On the other hand, this particularity regarding the "economic" position of the university could very well lead to lower wage premia as is the case in wages in general. Results of our study may resolve this opacity.

Below we follow the usual pattern. The first section sets our mission in the context of existing literature on the subject. In the second section, we provide a brief description of the Czech academic market and the data we used in our models. The third section develops the models while the last section discusses their results, followed by a conclusion.

\section{Literature review}

Wage premia seem anything but under-researched. Many attributes of employees were considered: from the salient like gender (e.g. Hospido and Moral-Benito 2016), race (Day \& Newburger 2002; Fang \& Heywood 2006), age (Stevens 2004) or marital status (Hersch \& Stratton 2000; Gorman 2000) to the surprising attributes like height $(\mathrm{Gu} \& \mathrm{Ji}$ 2019; Kim \& Han 2017), weight (Larose et al. 2016; Caliendo \& Gehrsitz 2016) or even beauty (Deryugina \& Shurchkov 2015; Dossinger et al. 2019). These studies show that the behavior of people on the labor market often can differ from what they are usually aware of. However, the most notorious (and most relevant to this text) is the research on the premium earned on education (see, e.g., Grogger and Eide 1995; Light and Strayer 2004; Lindley and Machin 2016; Lkhagvasuren 2014) seniority (Zwick 2008; Altonji \& Williams 2005) and ranks (Mertens \& Röbken 2013). In these cases, wage premiums are usually taken into account with full awareness of the employer and employee.

It can be expected that wage will grow with the level of education achieved as jobs which require better education naturally offer greater financial rewards. At the same time, the causality of the correlations found in the studies may be rather difficult to pinpoint. Specifically, the results of Mertens and Röbken (2013) show a positive correlation between having a doctoral degree and wages. However, is it the doctoral degree that increases the wage with all education and information acquired or is the driving variable the intelligence of the person which is important for the employer? The degree acquired would then be just a proxy variable for intelligence. Turning specifically to academia, wages were compared across different types of institutions (Hospido \& Moral-Benito 2016; Zoghi 2003) or countries (Angermuller 2017). Their relation to various attributes of productivity has been omnipresent from early on (De Fraja et al. 2018; Leahey 2007; Tuckman \& Tuckman 1976) and they were naturally recognized as an important factor in attracting productive faculty (Johnson 2010) or retaining them (Nagowski 2003). This aspect can be regarded as of great importance because financial environment has strong impact on the quality of services provided, in academia especially. Indeed, it can be surprising how many seemingly unimportant factors have to do with the functioning of certain institutions. Most of the other factors were looked into as well: from gender (Barbezat \& Hughes 2005; Kelly \& Grant 2012; Geisler \& Oaxaca 
1999) and age (Stevens 2004; Tuckman \& Tuckman 1976) to the number of coauthored publications (De Fraja et al. 2018), the length of tenure (Barbezat \& Hughes 2001; Ehrenberg et al. 1998), probability of tenure (Yang \& Webber 2015; Ehrenberg et al. 1998), seniority (Barbezat 2004; Monks \& Robinson 2001; Barbezat \& Donihue 1998) or academic ranks (June 2014; Renzulli et al. 2013). Unfortunately, most of such studies are restricted by the number and type of variables which are taken into account. As we will see later, this aspect is not negligible in our case either. Regarding the ranks and wages relationship, many authors have described what has come to be known as "salary compression". This phenomenon occurs when professors of a lower rank earn salaries close to - or even higher than - salaries of more senior faculty (see e.g. Cheslock and Callie 2015). Barbezat and Donihue (1998) found signs of potential compression in universities of business and economics. This was later corroborated by McDonald and Sorensen (2017) who attribute this to a rise in the opportunity cost of younger business faculty. In our case, the phenomenon of salary compression will be discussed as well but in general we are interested in the relationships of different academic ranks when it comes to salary, be it any significant difference between different academic ranks.

Lastly, with respect to the very institution we received data from, some hints at the wage distribution can be gleaned from its internal regulation on wages (UJEP 2009). This provides both wage ranges (p. 8) and extra top-ups for academic ranks (p. 12). Hence, for example, the wage maxima stipulated by this regulation for the three academic ranks are all 4 thousand CZK apart (i.e. 32, 36 and 40), while their top-ups (in the relevant order) are 1, 2 and 3 thousand CZK. All of these, however, are only optional amounts that may or may not be actually reflected in wages, which makes our investigation worthwhile.

Angermuller (2017) showed that many aspects of rewarding employees can differ across countries. Also, see, e.g., Wanhua and Jianbo (2012). The same most likely applies for different regions inside one country. This concept is very important for our work because our study investigates labor and wage environment in Czechia where such work has not yet been carried out. Thus, our work brings a regional perspective to the corresponding topic. Further, the many specifics of the investigated region may play a role in how the labor market is structured. The fact that there are many particularities regarding different regions is another reason why investigating the relationship between employment rank and finances can show new valuable insight. Altogether, the regional specification along with lack of similar studies makes the specified research questions valuable making the concept of our research worthwhile.

\section{Academic ranks in Czechia}

Peculiarities of individual universities aside, one can generally recognize three levels of ranks that go beyond the baseline, in ascending order: ${ }^{1}$

A graduate of a $\mathrm{PhD}$ program, hired by the HEI as an odborný asistent (roughly corresponding to the position of an assistant professor). While there is no perfect or necessary correspondence between the PhD degree and this academic rank, it is close enough to warrant considering faculty with $\mathrm{PhD}$ degrees as having achieved a higher rank than faculty without one. Henceforth then, we will label this rank as PhD.

Faculty awarded the rank of docent (analogous to associate professor).

Faculty awarded the rank of professor (analogous to full professor).

\subsection{Supply}

While all of these ranks are naturally conferred upon academics in different ways, all of them are transferable from one HEI to another: once acquired, they are equally valid and recognized beyond institutions that supplied them. All of them, including docent and professor ranks, thus behave like degrees and are supplied by universities accredited to do so by the government. ${ }^{2}$ Currently, out of the 62 existing higher education institutions, 29 offer at least one PhD program, 26 are authorized to supply docent ranks, and 25 of them are authorized to supply professor ranks. In all three categories, public universities absolutely dominate: only one private HEI is accredited to have a $\mathrm{PhD}$ program and virtually no private institutions are allowed to supply the remaining top 2 ranks.

The conditions for earning a $\mathrm{PhD}$ degree are determined by the accredited program. Conditions for awarding the higher ranks (docent and professor) are also subject to accreditation but their eventual application is more firmly in the hands of the awarding HEI: docents are approved by the scientific board of the respective division and awarded by the rector of the HEI, while professors (full professors) are approved successively by the scientific boards of both the division and the whole institution (HEI), and are ultimately awarded by the President of the Czechia. 


\subsection{Demand}

Faculty with these ranks are demanded by higher education institutions for two seemingly intertwined but really distinct reasons.

First, ranks, being awarded for past academic accomplishments, may serve as signals and predictors of faculty performance. For many positions, universities may naturally prefer faculty with a rank rather than without one or faculty with a higher rank to a faculty with a lower rank.

Second, HEIs demand ranked faculty to meet accreditation standards required by the government authority - National Accreditation Bureau for Higher Education - to legally operate and provide higher education within Czechia. As of September 2019, there were 28 public and 34 private HEIs, all competing for ranked faculty to staff their programs. Although the more and better the faculty is ranked, the better the accreditation authority considers the program to be, there are some stringent baseline requirements. For example, while the baseline for any faculty at HEI is the master's, some courses-courses that are central to the field of the program-must even in bachelor level programs be staffed and the whole program overseen ("guaranteed"), by faculty holding at least a $\mathrm{PhD}$ degree in the given area of expertise. In master's level programs, these requirements are ramped up towards faculty ranked as docent or professor. Interestingly enough and for the design of our study rather conveniently, the governmental standards for accreditations treat both of these ranks perfectly equally, which should, on this margin, eliminate this second source of demand for ranks: the existing wage premia of professors over docents should reflect the first source of demand only.

Other than that, it seems hard to disentangle the above two sources of the demand for ranked faculty from each other, given that all HEIs are subject to both. One may be perhaps somewhat skeptical about the importance (or at least primacy) of the first motivation: rank may not be the best predictor available to HEIs to estimate faculty's performance (especially if tenured as a result of the rank) and personal anecdotal evidence from the HEI administration suggests it is indeed easily substitutable. On the other hand, the second purpose for which ranked faculty is demanded cannot really be compensated; there is no alternative to hiring ranked faculty, it is a fixed cost of running any program. Thus, we do not see how much the ranks would be demanded as quality signals because many of them must be hired in the first place.
From the description above it is clear that some HEIs are on both sides of the market and are able to satisfy its own demand in an almost selfsustaining fashion (the more ranked faculty the HEI produces, the more likely it will be able for the HEI to renew its accreditation to produce ranked faculty in the future). This suggests that in those HEIs the wage premia of ranked faculty should be lower.

\section{Data and method}

The data on contracts and employees come from a Czech regional university - Jan Evangelista Purkyně University in Ústí nad Labem. The data, kindly provided by the university administration, had been stripped of all personal identifiers and each individual had been given a unique identification number. The data included a total of 1430 contracts the university had as of November 30, 2017 with its 1006 employees, each of the contracts being described by an array of variables related to the contracts or to the employee. Based on the above data, we constructed a dataset with the following variables (Table 1):

All of these variables were taken into account in order to construct linear regression models. In these even variables which are not of primary concern, they need to appear in order to control their effect which may intermingle with the effect of variables which we are interested in the most. While we are predominantly interested in the difference between the 3 academic ranks $\left(E_{d u c}, E_{0 d u c}\right.$ and $E_{6 d u c}$ ) we control for and report a full suite of educational levels $\left(E^{2} \mathrm{C}_{1}\right.$ through Educ $_{5}$ ), all of which seem straightforward except for Educ 5 . This is a degree somewhat specific to the Czech environment, awarded to graduates of selected master level programs who opt to undergo an additional exam and defend a thesis.

Besides the educational level dummies, the choice of most control variables is obvious. A special explanation is perhaps in order with respect to ContractsTotal, DivisionsTotal and RectorateJob. Even though most employees have just one contract within the whole institution, their total number as well as the number of different divisions at which the employees are contracted both turned out significant in explaining the wage level. The intuitive reason behind this is that both of these employee attributes are perhaps indicative of the demand for them. Similarly, having at least one contract with the central administrative division (rectorate) implies some sort of managerial position with its effect on wage level. 
Table 1 Description of Variables

\begin{tabular}{|c|c|c|}
\hline & Variable & Description \\
\hline \multirow{8}{*}{ 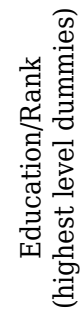 } & Educ $_{1}$ & Not having finished secondary education with a school leaving certificate (default) \\
\hline & $\mathrm{Educ}_{2}$ & Secondary education with a school leaving certificate \\
\hline & $\mathrm{Educ}_{3}$ & Bachelor level tertiary education \\
\hline & $\mathrm{Educ}_{4}$ & Master level tertiary education \\
\hline & $\mathrm{Educ}_{5}$ & Higher master level tertiary education \\
\hline & Educ $_{6}$ & Doctoral level tertiary education - PhD rank \\
\hline & Educ $_{0}$ & Docent rank (default category) \\
\hline & $\mathrm{Educ}_{7}$ & Profesor rank \\
\hline \multirow{7}{*}{ 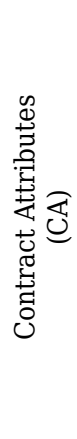 } & Wage & Contracted gross monthly wage in CZK \\
\hline & Size & Size of the contract, 1.0 being the full-time contract \\
\hline & Indeterminate & $\begin{array}{l}\text { Dummy indicating whether (at least one) contract is indeterminate in its duration. } \\
(\mathrm{Yes}=1, \mathrm{No}=0)\end{array}$ \\
\hline & Academic & $\begin{array}{l}\text { Dummy indicating whether (at least one) contract content is of academic nature. } \\
\left(\text { Yes }=1, \mathrm{No}_{0} \text { ) }\right.\end{array}$ \\
\hline & Project & $\begin{array}{l}\text { Dummy indicating whether (at least one) contract is related to a project, typically a research project. } \\
\left(Y e s=1, \mathrm{No}^{\prime}=0\right)\end{array}$ \\
\hline & History & Historical duration of the contract (of the oldest contract in aggregated contracts) in years \\
\hline & School $_{1 . .8}$ & $\begin{array}{l}\text { Dummies for one of } 8 \text { schools (university divisions) the contract relates to } \\
\text { (Default: non-school divisions). }\end{array}$ \\
\hline \multirow{5}{*}{ 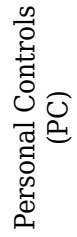 } & Gender & Employee's gender \\
\hline & Age & Employee's age \\
\hline & ContractsTotal & Total number of contracts of the employee within the university \\
\hline & DivisionsTotal & Number of different divisions (schools) within university the employee has contracts with \\
\hline & RectorateJob & $\begin{array}{l}\text { Dummy indicating whether the employee has at least one contract at the rectorate. } \\
(\text { Yes }=1, \mathrm{No}=0 \text { ) }\end{array}$ \\
\hline
\end{tabular}

\subsection{Contract aggregation}

The faculty is contractually involved with the university in various ways and not all of them may reflect the ranks in the same way. Moreover, very often these contracts are not unrelated to each other and the individual contracts may be set to serve other purposes. There might be reasons (having to do e.g. with the source of financing) for money being channeled to faculty through one rather than the other contract and faculty may only care about what the whole package of contracts boils down to (e.g. an unreasonably low wage in one contract may be compensated to faculty by another unreasonably high wage contract). All of this has little to do with ranks and is introducing noise that can be reduced by some form of contract aggregation. In our models then, we work with 3 different levels of aggregation:

1. Unaggregated

No aggregation performed, each of the 1430 contracts taken as an independent instance.

2. Within-school aggregation

All contracts of an employee within the particular school were aggregated into one, so that each employee appears in the dataset more than once only if they are involved with more than one school. This reduced the number of contracts in the dataset from 1430 to 1041.

\section{Total aggregation}

All contracts of an employee in the whole university were aggregated into one, so that each employee appears in the dataset only once. This reduced the number of contracts in the dataset to 1006 (corresponding to the number of employees).

The process of aggregation raised some issues as not all contract variables are either individually invariable (all personal control variables and education/rank dummies) or easily amenable to aggregation/summation (Wage, Size). Aggregation of such contract-specific attributes was then subject to some arbitrary decisions: the dummies Academic, Indeterminate and Project were set to 1 as long as at least one of the individual contracts had these attributes equaling 1, and the History took on the value of the individual contract with the longest history. 


\subsection{Models}

Based on the 3 different levels of aggregation (none, within-school, total), we have created 3 datasets, each of which we analyzed through a series of 12 OLS regression models with Wage being the dependent variable. This method was chosen because the dependent variable Wage is clearly a continuous variable. It could be argued that the upper boundary does not exist at a theoretical level, it is relevant to expect that in reality this boundary exists. In either case, OLS regression is relevant to use. A similar methodological approach has been also chosen by Mertens and Röbken (2013) and also Monks and Robinson (2001). Another issue is the question of linearity; it is possible that the relationship of some independent variables with the dependent variable is not linear, we refrain from studying this in much detail since the variables we are talking about (e.g., Age) are not of primary concern. The constructed models are:

1. 2 pooled models with school fixed effects: model 1 on unrestricted (full) dataset and model 3 on dataset restricted to contracts with academic, as opposed to administrative, divisions (schools-only), specified as:

$$
\begin{aligned}
\text { Wage }= & \text { const }+\sum_{i=1}^{7} \beta_{i} \text { educ }_{i}+\sum_{j=1}^{c} \gamma_{i} C A_{j}+ \\
& \sum_{k=1}^{p} \pi_{k} P C_{k}+\sum_{l=1}^{8} \sigma_{l} \text { school }_{l}+\epsilon
\end{aligned}
$$

Where

Educ is a vector of the 7 educational level dummy variables (with the docent category omitted as a default) with corresponding regression coefficients $\beta_{i}$;

$C A$ is a vector of $c$ contract attributes with corresponding regression coefficients $\gamma_{j}$;

$P C$ is a vector of $p$ personal control variable with corresponding regression coefficients $\Pi_{k}$;

School is a vector of 8 school dummy variables for each of the 8 schools (with the nonschool division default) with corresponding regression coefficients $\sigma_{l}$.
2. 2 pooled models without school fixed effect: model 2 on unrestricted (full) dataset and model 4 on dataset restricted to schoolsonly, specified as:

$$
\begin{aligned}
\text { Wage }= & \text { const }+\sum_{i=1}^{7} \beta_{i} E d u c_{i}+\sum_{j=1}^{c} \gamma_{i} C A_{j}+ \\
& \sum_{k=1}^{p} \pi_{k} P C_{k}+\epsilon
\end{aligned}
$$

3. 8 models with dataset restricted always to one particular school at a time (school-specific models), specified the same way as in 2).

The above 12 models per each of the 3 datasets provide a total of 36 models, all of which yield a vector of coefficients estimating the wage premia at all levels of education compared to docents. We will be most interested in $\beta_{6}$, the hypothesized substantial (negative) premium of PhDs over docents, and $\beta_{7}$, the hypothesized not-so-large premium of professors over docents.

However, not all of these models should be considered equally informative. Models with an unrestricted dataset (models 1 and 2), for instance, include data on all contracts and are thus more contaminated with contracts of employees who are not academics than models restricted to academic divisions of the university (i.e. models 3 and 4 , and 5 through 12). Similarly, models with fixed effects for individual schools (models 1 a 3), given their substantial differences determined by fields, could be considered universally superior to the model without such fixed effects (models 2 a 4). Additionally, as pointed out above, some level of aggregation seems desirable which makes models on unaggregated data (models 1a through 12a) less preferred.

\section{Results}

All $\beta$ estimates from all models can be found in the Appendix, offering also averages of estimates across all models with particular levels of aggregation, as well as averages across all models of identical specification and dataset restrictions.

Generally, the $\beta$ values in most models match intuition by reflecting the ordinal nature of levels of education and ranks: the only positive premium over docents is enjoyed by professors, while all the other premia are negative and increasingly so towards the lower levels. Hence, the phenomenon of salary 
compression (e.g.Cheslock and Callie 2015) does not seem to appear at the university. This can be regarded as a particularity of the regional university studied because Barbezat and Donihue (1998) found the signs of salary compression in the United States. Indeed, it is possible that salary compression is not in general present in Czech schools. However, due to a lack of similar data from other Czech universities, this hypothesis will yet remain unconfirmed.

There are only two models (6 and 12) that defy the general pattern described above: almost none of the $\beta$ coefficients in those models came out as significant at any conventional level and even their values seem counterintuitive. We certainly do not want to succumb speedily to the temptation to dismiss uncomfortable data and results (the contracts from these schools are still included in the pooled models, i.e. models 1 through 4) but as these results appear throughout all three levels of aggregation, it seems fair to speculate that this is due to some school-specific factors and discount the relevance of the results from models 6 and 12 appropriately.

Besides these two peculiar school-specific models, looking at individual education levels across all models, the premium of higher master level education $\left(\mathrm{Educ}_{5}\right)$ stands out in most models by lagging behind the regular master level education $\left(\mathrm{Educ}_{4}\right)$ and being more on par with bachelor level tertiary education $\left(\mathrm{Educ}_{3}\right)$. This result may run contrary to expectations but is largely insignificant as there are only 17 employees with this level of education in the whole dataset. ${ }^{3}$

When interpreting the results, it should be taken into account that the relationship between academic rank or education and wages often differs across schools as has been shown, for example, by Cheslock and Callie (2015). This probably explains our results which are also different in different schools observed in our study. The fact that PhDs earn more than less educated people has also been pointed out by Mertens and Röbken (2013). The core of our analysis is to investigate the wage premia of associate professors and professors and to compare it with other studies of this sort. This area is investigated below.

\subsection{Docents (associate professors) over PhDs}

Going more specifically to the value of $\beta_{6}$, it seems convincingly negative in almost all models as expected. In fact, it is only the two models mentioned above (6 and 12) where this coefficient does not come out as negative at conventional levels of significance.
The estimated values depend heavily on both the level of aggregation and the data restriction, with the average effect ranging from over 1 thousand in models using the unaggregated and unrestricted data (models 1a and 2a) to well over 7 thousand in models using individually aggregated data restricted to particular schools with the outlier schools left out (models $5 \mathrm{c}$ and $7 \mathrm{c}$ through $11 \mathrm{c}$ ), see Table 2.

Table 2 Average premium of docent over $\mathrm{PhD}$ in different classes of models

\begin{tabular}{|c|c|c|c|c|c|}
\hline $\begin{array}{l}\text { Classes } \\
\text { of models }\end{array}$ & 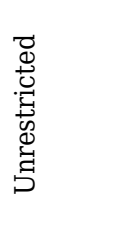 & 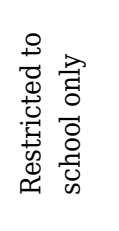 & 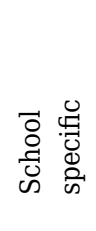 & 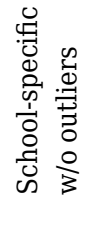 & $=\begin{array}{l}\frac{0}{8} \\
\frac{8}{8}\end{array}$ \\
\hline Model numbers & 1 and 2 & 3 and 4 & $5-12$ & $\begin{array}{l}5 \text { and } \\
7-11\end{array}$ & $1-12$ \\
\hline a) unaggregated & 1194 & 2965 & 3274 & 4690 & 2212 \\
\hline $\begin{array}{l}\text { b) division- } \\
\text { individual }\end{array}$ & 2418 & 5295 & 5934 & 7007 & 4070 \\
\hline c) individual & 2658 & 5510 & 5774 & 7206 & 4221 \\
\hline
\end{tabular}

In trying to narrow down this rather large range of estimates, one can recall that not all models are equally suitable for making inferences about the wage premia of academic ranks in particular (see the discussion of the models above). Zeroing in on the academic divisions of the whole institution (i.e. schools, models 3 through 12) and using some form of contract aggregation (models $b$ and $\mathrm{c}$ ), we obtain estimates of $\beta_{6}$ all between 5 and 6 thousand CZK or $18 \%$ to $21 \%$ of the average regional wage. ${ }^{4}$ This seems quite sizeable, even though it is still a rather conservative estimate, unaffected by even higher estimates one would be tempted to report by leaving the outlier schools out. Our results do not indicate that the docents (associate professors) are "stuck in the middle" as described by Jun (2014). This can be attributed to the fact that specific conditions in the university play a role here.

Since docents almost always take part in publication activities, it would be valuable to find out if docents with a higher specialization earn more money than those with less specialized degrees as is the case in the study of Leahey (2007). However, case data about specializations was not possible to gather. Thus, we leave this aspect for further research. 


\subsection{Professors (full professors) over docents}

The $\beta_{7}$, indicating the premium of professors over docents, turned out to be generally more substantial than hypothesized. While in the models on pooled data it turned out significant and positive, in the school-specific models the story appears bifurcated: in one half of the models $(6,7,8$ and 10), the premium is sizable and significant, averaging over 8 thousand, whereas in the other half of them $(5,9$, 11 and 12) it is indeed insignificant as hypothesized. The averages provided by different groups of models are tabulated (Table 3) below.

Table 3 Average premium of a professor over docent in different classes of models

\begin{tabular}{|c|c|c|c|c|c|}
\hline $\begin{array}{l}\text { Classes of } \\
\text { models }\end{array}$ & 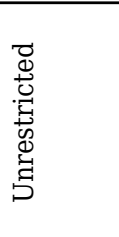 & 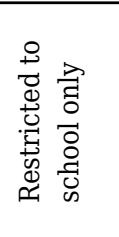 & 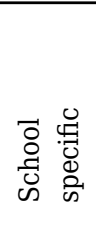 & 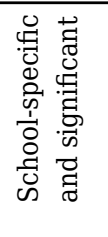 & 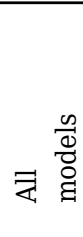 \\
\hline Model numbers & 1 and 2 & 3 and 4 & $5-12$ & $\begin{array}{l}6-8 \\
\text { and } 10\end{array}$ & $1-12$ \\
\hline unaggregated & 3266 & 2142 & 2807 & 4224 & 2776 \\
\hline division-individual & 6027 & 4147 & 4015 & 8186 & 4998 \\
\hline individual & 5913 & 4069 & 4220 & 8523 & 4956 \\
\hline
\end{tabular}

The approach we would normally tend to rely on most (looking at models with pooled data from schools and at average of school-specific models) delivers premium estimates of around 4 thousand CZK (or $14 \%$ of the regional average), which are the mean of, but quite unlike, what is going on at any of the 8 schools in the institution. If we nonetheless took this as indicative of the mean professor's premium, it is certainly not negligible, even though it indeed seems slightly lower than the mean premium of docents. These results correspond with the outcome of the study of Monks and Robinson (2001). If we studied only the correlation between academic ranks and wages, there would be the danger of misinterpreting the correlation results as causalities. For example, the reason why professors earn more money could be their higher age and more experience. By controlling the effect of age, we avoid this problem as far as age of academicians is concerned. However, this is not the case with experience and publication results (for studying the relationship between publication results and wages see, e.g., De Fraja et al. 2018 or Tuckman and Tuckman 1976). This was mentioned as one of the possible shortcomings of our research.
It is hard to interpret such starkly contrasting but balanced outcomes. The only safe conclusion here is that the data certainly does not suggest that taking the last step in the academic ranking is always associated with earning extra income.

Further, one cannot be certain if our results would correspond with similar aspects in other universities. The region of the university studied in this paper is one of the poorest in Czechia. It is likely that this has an effect on the wage structure in the university as well. Furthermore, our results correspond with the findings of Barbezat (2004) who did not find any salary compression in some American schools.

In general, our data shows that with other factors fixed, achieving higher education or rank level correlates with having a higher wage. This corresponds with similar findings from other areas besides academia (see, e.g., Grogger and Eide 1995).

\section{Discussion and conclusions}

Our above analysis of a unique wage dataset offers some quantitative content to the intuitive notion that higher levels of education and academic ranks associate with higher wage levels. However, comparing the two premia, which were the focus of this study, we tend to conclude that the premium of docents over PhDs is much more pronounced and clear than the premium of professors over docents.

This is in stark contrast with wage premia appearing e.g. in US academia. Data on average wages collected and reported by the American Association of University Professors (AAUP 2018, p. 18) suggests that the situation is flipped: full professors enjoy a premium over associate professors that is about 3 times as large as the premium of associate professors over assistant professors.

The main reason why such research would be worth conducting in other universities is that results would be interesting to compare with other educational institutions. As mentioned in the first part of this paper, the Northwest region of Czechia is very specific owing to its unique history and position in Czechia.

It is important to highlight the fact that academic ranks are important for accreditations of the university study programs. This is partly why higher academic ranks are of such importance. Being founded in 1991, the university we are studying is relatively new in the context of Czechia. Owing to its regional character, and its newcomer status, the university may still be subject to different levels of accredita- 


\section{S sciendo}

tion standards enforcement compared to more established institutions in other regions.

This specific positions can be a source of disparity when compared to the rest of Czech universities. It is important to mention that the methodology used in our research is not perfect as far as our goals were specified. For example, there is the problem of lack of causality indication in the correlation analysis - see the literature review section for an explanation concerning this problem.

As for the research questions specified in the introduction, the results of this study were able to answer all of them. Overall, the results are quite unsurprising and therefore may be considered as not too exciting. As unique as the dataset was, we were to some extent blinded by the unavailability of some crucial information that would have assisted us in shrinking the ranges of estimation. Perhaps most importantly, the dataset lacked any information that would enable us to control for actual performance, academic or administrative. Another area worth investigating would be to test if the wage premia for academic ranks applies more to men or to women as is done in the case of Grogger and Eide (1995). Possibly it might not apply for one of the genders at all. With our data this would be rather difficult due to the lack of observations (people included in the research) in the schools which we study. Thus, this would also be a good subject for further research.

Although pointing out these shortcomings may come across as suggestions for future research, it is not very likely that such datasets would be available as this would substantially facilitate the identification of individual employees in the previously (and necessarily) anonymized data. The most obvious way to follow up and improve upon our research is the time-honored replication, especially in private HEIs, which may operate quite differently in these respects from public universities.

\section{Footnotes}

1 This is corroborated by the fact that the accreditation authority in the Czechia (much like many elsewhere) requires faculty information to be broken down into these categories.

2 The highest academic rank (profesor) is legally conferred upon academics not by the university (which only makes nominations) but by the president of Czechia. Several notable exceptions notwithstanding, this is a largely formal step: it is still the universities that effectively supply this rank.

${ }^{3}$ The $\beta_{5}$ coefficients do come out as very significant in some models but this refers to the docents being the default category $\left(\mathrm{Educ}_{0}\right)$. So, while we may reject the null hypothesis that employees with $E d_{c_{5}}$ enjoy the same wage level as $\operatorname{Educ}_{0}$ (i.e. that $\beta_{5}=0$ ), it does not imply anything about $\beta_{5}$ being significantly different from other $\beta$ coefficients. For instance, if $\mathrm{Educ}_{4}$ is set as a default category, neither $\beta_{5}$ nor $\beta_{3}$ appear significant.

${ }^{4}$ In 2017 , the average wage in the region amounted to 28369 CZK (Czech Statistical Office, 2021).

\section{Acknowledgements}

We thank the Operational Programme Research, Development and Education of the Czech Republic for financing the project "Doctoral School - Applied and Behavioral Studies" - project number CZ.02.2.69/0.0/0.0/16_018/0002727 


\section{References}

AAUP (2018) The annual report on the economic status of the profession, 2017-2018. Academe.

Altonji J, Williams N (2005) Do wages rise with job seniority? a reassessment. ILR Review 58(3):370-397. doi: 10.1177/ 001979390505800304

Angermuller J (2017) Academic careers and the valuation of academics. a discursive perspective on status categories and academic salaries in france as compared to the u.s., germany and great britain. Higher Education 73(6):963-980. doi: 10.1007/s10734-017-0117-1.

Barbezat D (2004) A loyalty tax? national measures of academic salary compression. Research in Higher Education 45(7): 761-776. doi: 10.1023/B:RIHE.0000044230.25883.46.

Barbezat D, Donihue M (1998) Do faculty salaries rise with job seniority? Economics Letters 58(2):239-244. doi: 10.1016/ S0165-1765(97)00272-3.

Barbezat D, Hughes J (2001) The effect of job mobility on academic salaries. Contemporary Economic Policy 19(4) 409-423. doi: 10.1093/cep/19.4.409.

Barbezat D, Hughes J (2005) Salary structure effects and the gender pay gap in academia. Research in Higher Education 46(6) 621-640. doi: 10.1007/s11162-004-4137-1.

Caliendo M, Gehrsitz M (2016) Obesity and the labor market: A fresh look at the weight penalty. Economics Human Biology 23:209-225. doi: 10.1016/j.ehb.2016.09.004

Cheslock J, Callie T (2015) Changing salary structure and faculty composition within business schools: Differences across sectors and state funding levels. Economics of Education Review 49:42-54. doi: 10.1016/j.econedurev.2015.08.001

Day J, Newburger E. The big payoff: Educational attainment and synthetic estimates of work-life earnings. Technical report (2002). Special Studies. Current Population Reports.

De Fraja G, Facchini G, Gathergood J (2018) Academic salaries and public evaluation of university research: Evidence from the uk research excellence framework (ssrn scholarly paper id 2815174. Social Science Research Network. Available at:

Deryugina T, Shurchkov O (2015) Now you see it, now you don't: The vanishing beauty premium. Journal of Economic Behavior Organization 116:331-345. doi: 10.1016/j.jebo.2015.05.007.

Dossinger K, Wanberg C, Choi Y, Leslie L (2019) The beauty premium: The role of organizational sponsorship in the relationship between physical attractiveness and early career salaries. Journal of Vocational Behavior 112:109-121. doi: 10.1016/j.jvb.2019.01.007.

Ehrenberg R, Pieper P, Willis R (1998) Do economics departments with lower tenure probabilities pay higher faculty salaries? The Review of Economics and Statistics 80(4):503-512. doi: $10.1162 / 003465398557780$.

Fang T, Heywood J (2006) Output pay and ethnic wage differentials: Canadian evidence. Industrial Relations: A Journal of Economy and Society 45(2):173-194. doi: 10.1111/j. 1468-232X 2006.00423x.

Geisler I, Oaxaca R. Faculty salary determination at a research i university. (1999).
Gorman E (2000) Marriage and money: The effect of marital status on attitudes toward pay and finances. Work and Occupations 27(1):64-88. doi: 10.1177/0730888400027001004.

Grogger J, Eide E (1995) Changes in college skills and the rise in the college wage premium. The Journal of Human Resources 30(2):280-310. doi: 10.2307/146120.

Gu T, Ji Y (2019) Beauty premium in china's labor market: Is discrimination the main reason? China Economic Review 57: 101335. doi: 10.1016/j.chieco.2019.101335.

Hersch J, Stratton L (2000) Household specialization and the male marriage wage premium. ILR Review 54(1):78-94. doi: 10.1177/001979390005400105.

Hospido L, Moral-Benito E (2016) The public sector wage premium in spain: Evidence from longitudinal administrative data. Labour Economics 42:101-122. doi: 10.1016/j.labeco. 2016.08.001.

Johnson G (2010) What Is It That Satisfies Faculty? Rank as a Consideration in Factors Related to Job Satisfaction. Association for Institutional Research, University of Minnesota.

June A (2014). Stuck in the middle. the chronicle of higher education.

Kelly K, Grant L (2012) Penalties and premiums: The impact of gender, marriage, and parenthood on faculty salaries in science, engineering and mathematics (sem) and non-sem fields. Social Studies of Science 42(6):869-896. doi: 10.1177/ 0306312712457111.

Kim T, Han E (2017) Height premium for job performance. Economics Human Biology 26:13-20. doi: 10.1016/j.ehb.2017. 01.002

Larose S, Kpelitse K, Campbell M, Zaric G, Sarma S (2016) Does obesity influence labour market outcomes among working-age adults? evidence from canadian longitudinal data. Economics Human Biology 20:26-41. doi: 10.1016/j.ehb.2015.09.007.

Leahey E (2007) Not by productivity alone: How visibility and specialization contribute to academic earnings. American Sociological Review 72(4):533-561. doi: 10.1177/ 000312240707200403

Light A, Strayer W (2004) Who receives the college wage premium? assessing the labor market returns to degrees and college transfer patterns. Journal of Human Resources 39(3): 746-773. doi: 10.3368/jhr.XXXIX.3.746.

Lindley J, Machin S (2016) The rising postgraduate wage premium. Economica 83:281-306. doi: 10.1111/ecca.12184

Lkhagvasuren D (2014) Education, mobility and the college wage premium. European Economic Review 67:159-173. doi: 10.1016/j.euroecorev.2014.01.011.

McDonald J, Sorensen J (2017) Academic salary compression across disciplines and over time. Economics of Education Review 59:87-104. doi: 10.1016/j.econedurev.2017.06.003.

Mertens A, Röbken H (2013) Does a doctoral degree pay off? an empirical analysis of rates of return of german doctorate holders. Higher Education 66(2):217-231. doi: 10.1007/ s10734-012-9600-x.

Monks J, Robinson M (2001) The returns to seniority in academic labor markets. Journal of Labor Research 22(2):415-426. doi: 10.1007/s12122-001-1043-6.

Nagowski M (2003). Associate professor turnover in american college and universities. 


\section{S sciendo}

Renzulli L, Reynolds J, Kelly K, Grant L (2013) Pathways to gender inequality in faculty pay: The impact of institution, academic division, and rank. Research in Social Stratification and Mobility 34:58-72. doi: 10.1016/j.rssm.2013.08.004.

Stevens P (2004) Academic salaries in the uk and us. National Institute Economic Review 190(1):104-113. doi: 10.1177/ 002795010419000110.

Tuckman B, Tuckman H (1976) The structure of salaries at american universities. The Journal of Higher Education 47(1):51-64. doi: $10.2307 / 1978713$.

UJEP (2009). Vnitřní mzdový předpis univerzity jana evangelisty purkyně v Ústí nad labem. Available at:https://www.ujep.cz/ wp-content/uploads/ 2017/05/VMP_0806091.pdf.

Wanhua M, Jianbo W (2012) A study on academic salary and remunerations in china. In Altbach P, Reisberg L, Yudkevich M, Androushchak G, Pacheco I, eds., Paying the Professoriate: A Global Comparison of Compensation and Contracts page 104-113. Routledge New York.

Yang L, Webber K (2015) A decade beyond the doctorate: The influence of a us postdoctoral appointment on faculty career, productivity, and salary. Higher Education 70(4):667-687. doi: 10.1007/s10734-015-9860-3.

Zoghi C (2003) Why have public university professors done so badly? Economics of Education Review 22(1):45-57. doi: 10.1016/S0272-7757(01)00058-9.

Zwick T (2008) The employment consequences of seniority wages (ssrn scholarly paper id 1207210. Social Science Research Network. Available at:. 


\section{S sciendo}

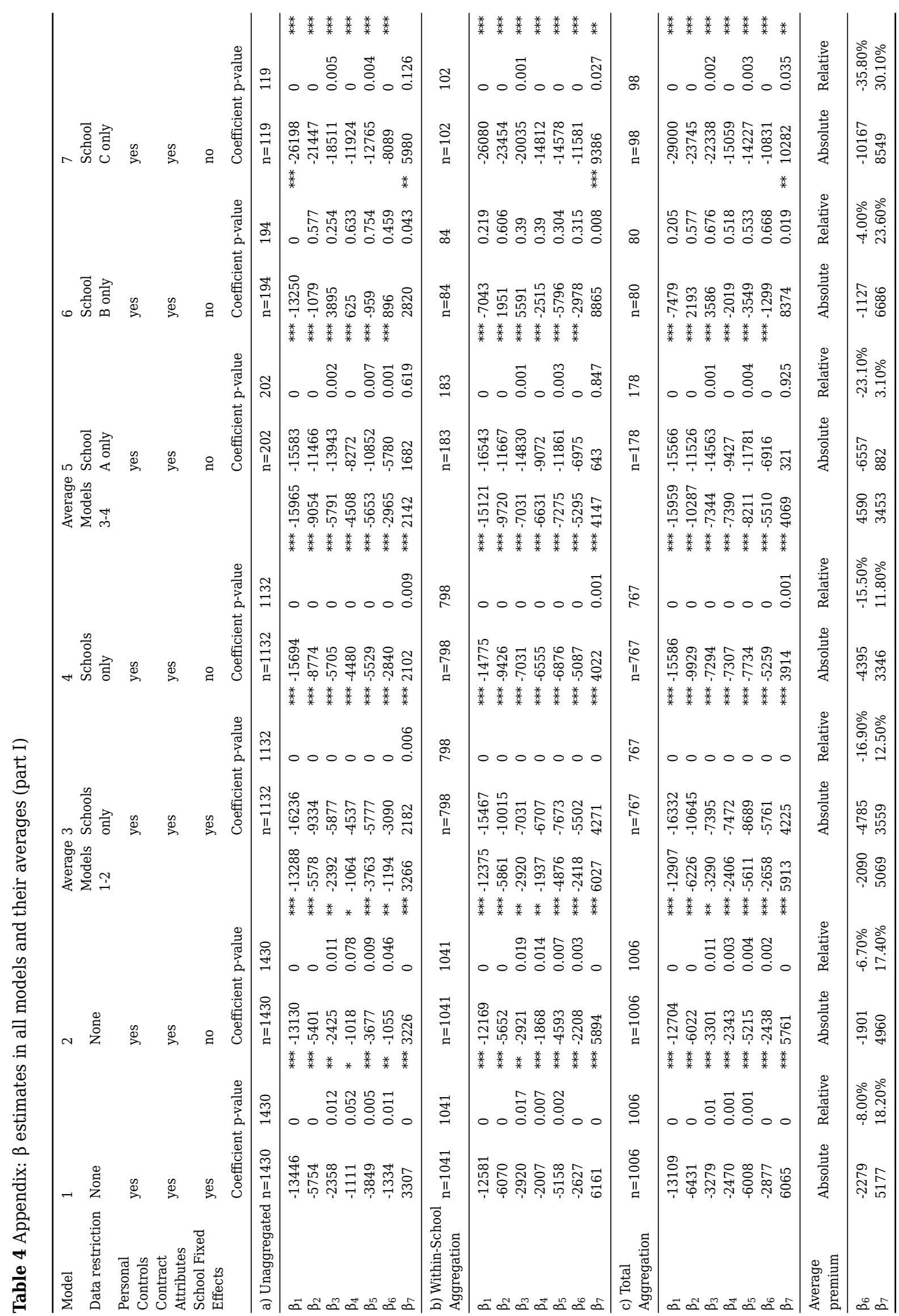




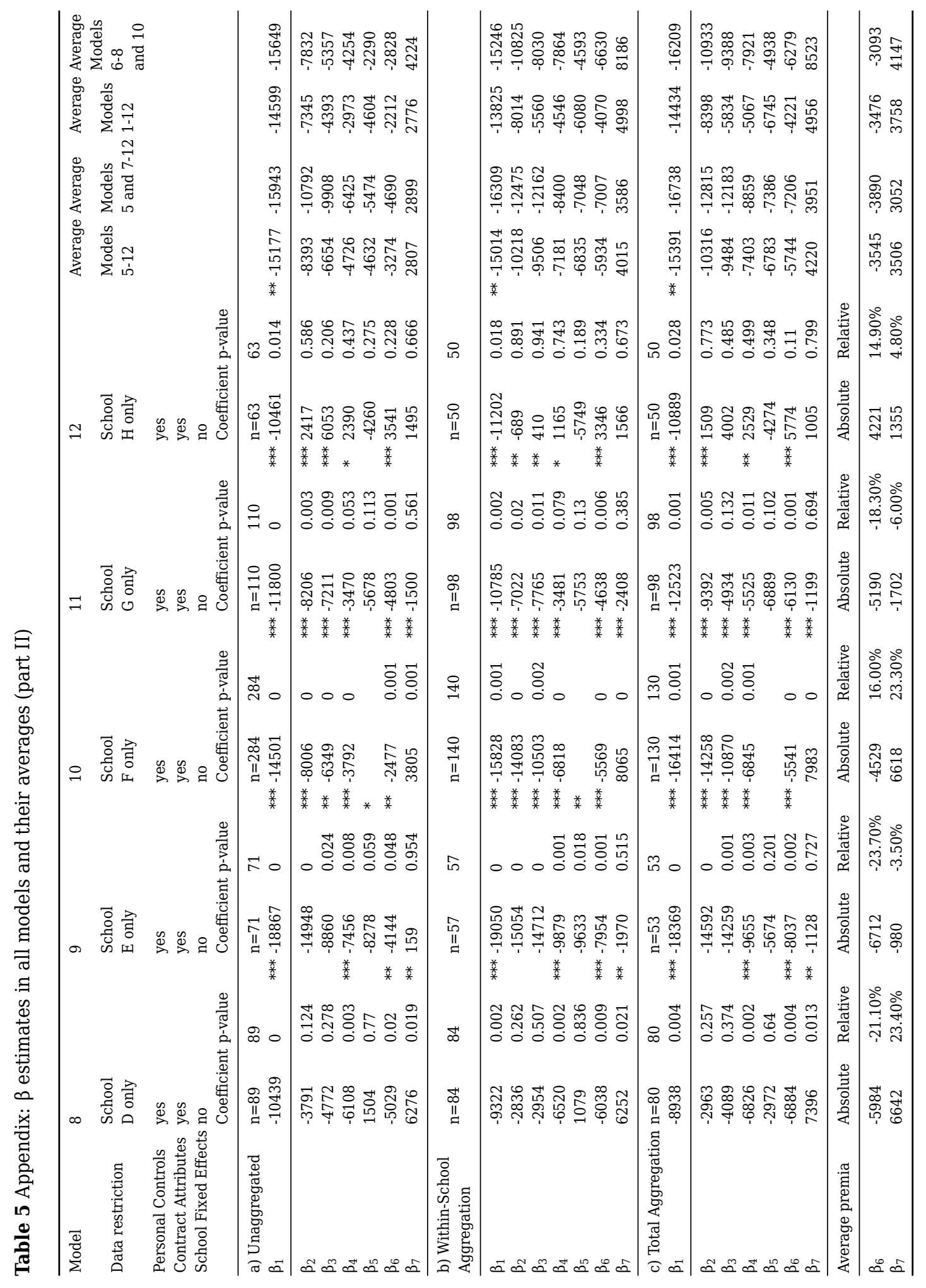

